\title{
El proyecto de estructuras en el Museo de las Peregrinaciones (Santiago de Compostela)
}

\section{The structural project in the Museum of Pilgrimage (Santiago de Compostela)}

J. Estévez $^{(*)}$, E. Martín ${ }^{*}$, D. Otero $\left.{ }^{*}\right)$

\section{RESUMEN}

El artículo describe el diseño estructural del Museo de las Peregrinaciones (Santiago de Compostela), proyectado por el reconocido arquitecto Manuel Gallego Jorreto. Se trata de una obra de rehabilitación en un entorno monumental, sometida a múltiples condicionantes externos e internos. Entre otros: áreas expositivas diáfanas, complejidad espacial, gestión de la luz natural, limitaciones de transporte y suministro, preservación y estabilización de fachadas con diferentes niveles de degradación, y hallazgo de restos arqueológicos. Se describen las soluciones metálicas empleadas a fin de resolver luces importantes con reducido peso. En todos los casos, estas estructuras fueron fabricadas y transportadas en fracciones para su posterior ensamblaje en obra.

Palabras clave: Rehabilitación de edificios; diseño estructural; estructura de acero; viga pared; forjado unidireccional; forjado metálico aligerado.

\section{ABSTRACT}

The article describes the structural design of the Museum of Pilgrimage (Santiago de Compostela), projected by the renowned architect Manuel Gallego Jorreto. It is a rehabilitation work in a monumental environment, subjected to multiple external and internal constraints. Among others: open exhibition areas, spatial complexity, management of the natural light, limitations of transport and supply, preservation and stabilization of facades with different levels of degradation, and discovery of archaeological remains. Several steel solutions are described, capable of resolving noticeable spans with low weight. In all cases, these structures were built and transported in fractions for reassembly in the construction site.

Keywords: Building rehabilitation; structural design; steel structure; wall beam; one-way floor slab; lightweight steel floor slab.

(*) Universidad de A Coruña (España)

Persona de contacto/Corresponding author: javier@udc.es (J. Estévez)

Cómo citar este artículo/Citation: Estévez, J., Martín, E., Otero, D. (2015). El proyecto de estructuras en el Museo de las Peregrinaciones (Santiago de Compostela). Informes de la Construcción, 67(537): eo64, doi: http://dx.doi.org/10.3989/ic.13.134.

Licencia / License: Salvo indicación contraria, todos los contenidos de la edición electrónica de Informes de la Construcción se distribuyen bajo una licencia de uso y distribución Creative Commons Reconocimiento no Comercial 3.o. España (cc-by-nc). 


\section{ANTECEDENTES}

El origen del Museo de las Peregrinaciones de Santiago de Compostela se remonta a 1951, fecha en la que se abordan las primeras iniciativas relacionadas con la creación de un museo enfocado a la peregrinación jacobea. No obstante, es en torno a 2006 cuando la institución experimenta un renovado impulso bajo la gestión del Consorcio de Santiago, organismo intergubernamental en el que participan las administraciones estatal, autonómica y local. En ese período se planifica una organización plurinuclear (1) estructurada en tres focos: la denominada Casa Gótica, la Casa del Cabildo, y, finalmente, la antigua sede del Banco de España (Figura 1). Ésta última se encuentra en la Plaza de las Platerías, en íntima relación con el conjunto monumental definido por la propia Catedral, el Claustro, y demás construcciones aledañas (Figura 2). Es precisamente esta privilegiada situación, en uno de los puntos de mayor afluencia turística, la que define su programa interno, caracterizado por la previsión de amplios espacios expositivos. El proyecto, obra del arquitecto Manuel Gallego Jorreto, ha conciliado adecuadamente los requisitos funcionales y los condicionantes del entorno, estableciendo un sugerente diálogo entre la neutralidad formal de la construcción preexistente y la concepción flexible y diáfana que define su intervención. Recientemente, el edificio ha sido premiado en la XII Bienal Española de Arquitectura y Urbanismo BEAU XII, dentro de la modalidad de Reconversión y Reutilización de Edificios y Recursos Existentes. Nuestra participación en el proceso, como consultores en el ámbito estructural, nos ha permitido desarrollar soluciones técnicas de diversa índole, acordes a los planteamientos de proyecto, y ajustadas a las singularidades del emplazamiento.

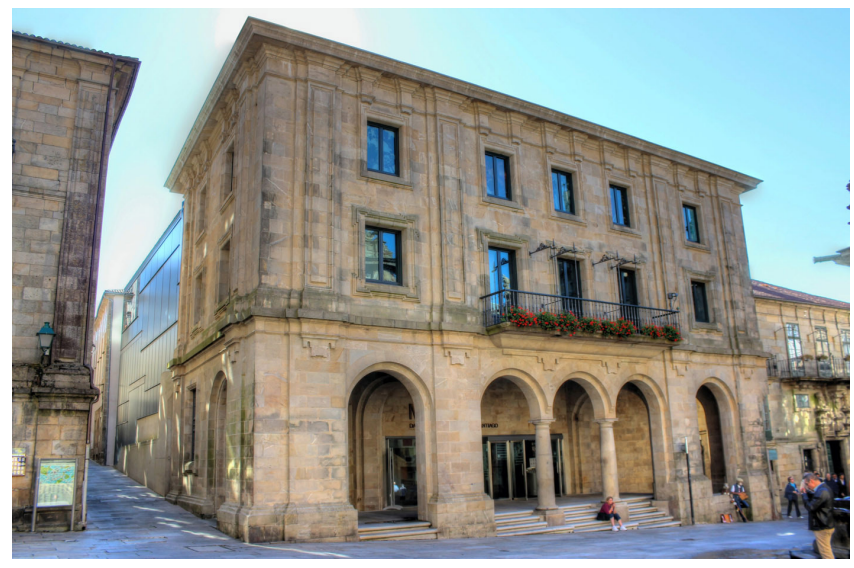

Figura 1. Edificio del Museo.

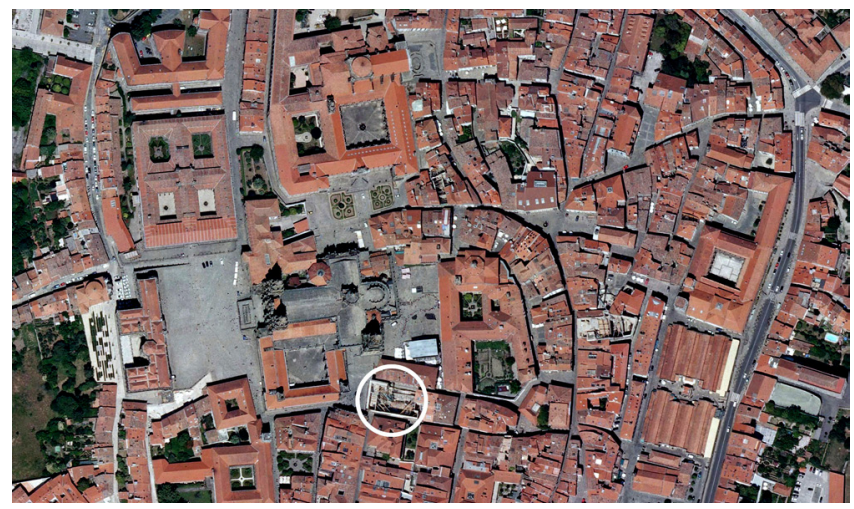

Figura 2. Emplazamiento junto a la Catedral de Santiago.

\section{EL EDIFICIO DEL BANCO DE ESPAÑA}

La construcción, obra del arquitecto Romualdo de Madariaga, finaliza en 1949 tras un largo proceso no exento de polémica (2), durante el cual se modificó el acceso en chaflán inicialmente previsto, y se disminuyó la altura del inmueble hasta igualar la de las denominadas casas de Espinosa, que anteriormente se elevaban en el mismo solar. Con todo, fueron desatendidos los informes que aconsejaban un retranqueo de la fachada principal (acorde a la alineación de la Casa de la Quintana), si bien esta pretensión se permuta por un soportal que no se integra plenamente en el espacio público por la diferencia de cota. Tras unas fachadas de aparente monumentalidad, la edificación escondía una sucursal bancaria de la época, organizada en las plantas baja y sótano, una distribución convencional de viviendas en los dos niveles superiores, y un reducido patio en el linde con la calle de la Conga.

El informe técnico redactado por el Ingeniero de C.C.P. Gustavo Vázquez Herrero entre 2007 y 2008, a instancias del Consorcio, revela una estructura horizontal básicamente resuelta mediante forjados nervados de hormigón armado y vigas de canto, con la excepción de la losa maciza que servía de cobertura a la primitiva cámara de seguridad. Por el contrario, la estructura portante vertical resulta notablemente heterogénea, al coexistir muros de hormigón ciclópeo, paños de fábrica de ladrillo de diferente factura, mezcla de ambas soluciones, y soportes de hormigón armado, en unos casos aislados y en otros adosados a las fachadas. Los testigos de hormigón extraídos en vigas y pilares mostraron una resistencia característica estimada en el intervalo 10-12 MPa, así como una profundidad de carbonatación preocupante, alcanzando en la mayoría de las piezas el nivel de la armadura. Ésta a su vez se ha resuelto con barras de acero lisas, propias de la época, con diámetros comprendidos entre 8 y $30 \mathrm{~mm}$, y con un límite elástico valorado en $220 \mathrm{MPa}$. En cualquier caso, los estudios efectuados a tenor de la capacidad de carga del sistema estructural reflejaron unas sobrecargas máximas estimadas muy inferiores a las exigibles, de acuerdo con la normativa vigente (3) y los nuevos usos previstos.

Tanto la propia configuración estructural como la necesidad de abordar un refuerzo de forma amplia y generalizada, entraban en conflicto con la propia concepción del museo como espacio público permeable y diáfano. Tales razones aconsejaron prescindir de la estructura preexistente en la nueva configuración, con la excepción de las fachadas que, pese a no ser patrimonio catalogado, han sido finalmente preservadas.

\section{DIRECTRICES GENERALES DE PROYECTO}

De acuerdo con los planteamientos del Consorcio, el museo se organiza en torno a una función básicamente expositiva, que afecta a la mayor parte de sus más de tres mil metros cuadrados. Por ello el proyecto contempla diferentes espacios de cierta amplitud y nula especialización, evitando en lo posible su compartimentación con objeto de favorecer la flexibilidad de uso.

La intervención incorpora el patio abierto, creado con el edificio bancario, a la nueva envolvente, recuperando así el carácter de manzana cerrada preexistente. La fracción añadida se resuelve mediante una piel vítrea, distinguiéndose plenamente de las fachadas pétreas adyacentes, pero relacionándose con ellas mediante aspectos geométricos como la localización de cornisas. Este ámbito comprende tres alturas 
con una cierta complejidad espacial, sirve de complemento al programa museístico, y adicionalmente facilita un acceso secundario a la cafetería.

Con estas consideraciones, el conjunto se desarrolla en una planta sensiblemente rectangular (Figura 3). Es posible distinguir un primer bloque formado por los dos vanos más próximos a la Plaza de Platerías. El primero comprende el soportal de planta baja, y aloja servicios e instalaciones a nivel de sótano y diferentes áreas expositivas en los pisos superiores. La segunda crujía se concibe como un núcleo organizativo, toda vez que comprende los elementos principales de circulación y los sucesivos vestíbulos de distribución.

El resto del volumen se fracciona según su dirección longitudinal mediante un vacío central de cuatro alturas, cuyo cometido es introducir iluminación cenital en el interior de las salas (Figura 4). Este ámbito se concibe así como eje compositivo de la intervención, definiendo, a través de la luz, sugerentes relaciones entre las distintas piezas que se abren a ambos lados del mismo.

Por último, en la banda más próxima a las medianeras se distribuyen diferentes locales de carácter interno (gestión, almacén, instalaciones y elementos privativos de circulación).

\section{ENTRAMADO INTERIOR}

Como se ha indicado con anterioridad, el proyecto se sitúa en pleno enclave monumental, con acceso a través de vías de reducidas dimensiones y sujeto a severas ordenanzas municipales. Tales circunstancias aconsejaban reducir en lo posible la construcción en hormigón armado o el suministro de grandes piezas pretensadas, con el objeto de minimizar la circulación de vehículos pesados. Por el contrario, parecía lógico optar por un entramado estructural mayoritariamente metálico, susceptible de ser fabricado de forma controlada en taller, trasladado al emplazamiento en fracciones adecuadas, y ensamblado finalmente a pie de obra mediante diferentes tipos de conexión.

Con estas premisas se proyectó un esqueleto estructural constituido fundamentalmente por perfiles tubulares, bien conformados, bien confeccionados como secciones armadas mediante soldadura de chapas.

El vaciado del solar, unido a la conservación de las fachadas, obligó a disponer sistemas de arriostramiento durante el período de construcción, fundamentalmente mediante soluciones espaciales debidamente trianguladas como resulta habitual (4). Asimismo, se hacía preciso estabilizar dichas fachadas en situación de servicio, en particular el lienzo que discurre en paralelo a la calle Xelmírez. Para ello se proyectó un pórtico parcialmente embebido en los niveles inferiores del mismo, practicando cajeados continuos a lo largo del paramento de hormigón ciclópeo en los que posteriormente se alojarían los perfiles tubulares del nuevo entramado. Para garantizar una adecuada conexión, los soportes se dotaron con alineaciones laterales de horquillas confeccionadas con barra corrugada, mejorando así la trabazón con el hormigón de relleno (Figuras 5 y 6).

En el interior, y en paralelo a esta fachada, discurre el lucernario longitudinal que, como ya se ha comentado, se encarga de proporcionar luz natural a cuatro niveles de áreas expositivas. Este cañón de luz aparece delimitado por dos planos resistentes con una separación a ejes de tan sólo $2,10 \mathrm{~m}$. Por otro lado, en planta baja se requería extender
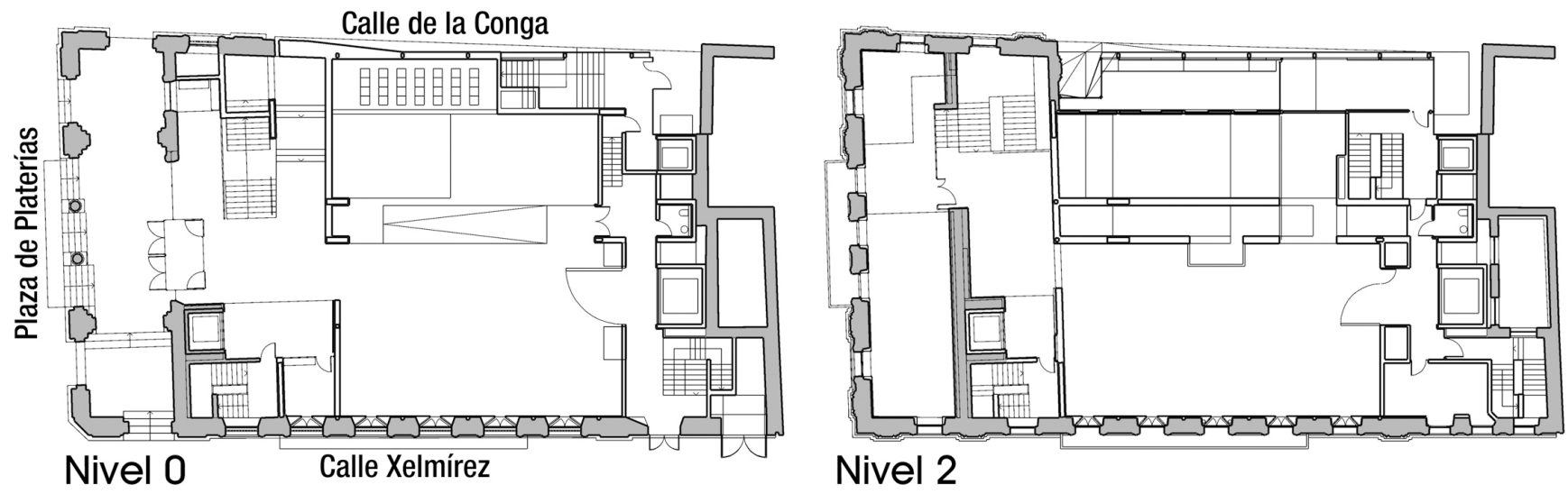

Nivel 2

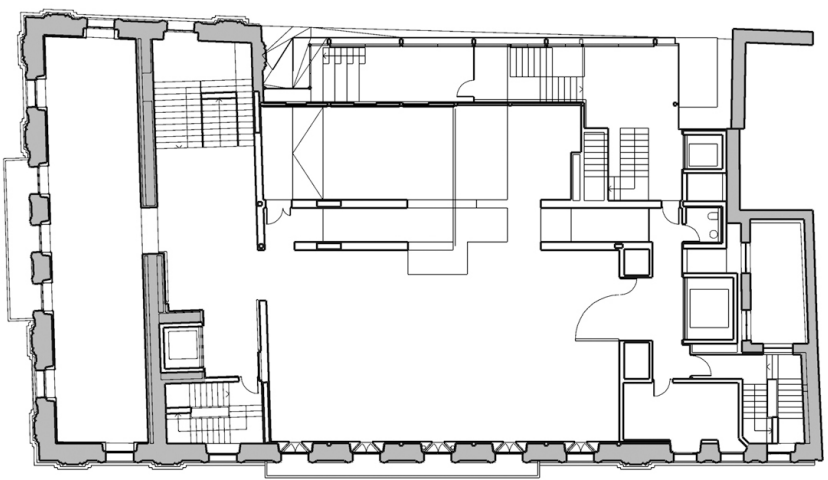

Nivel 1

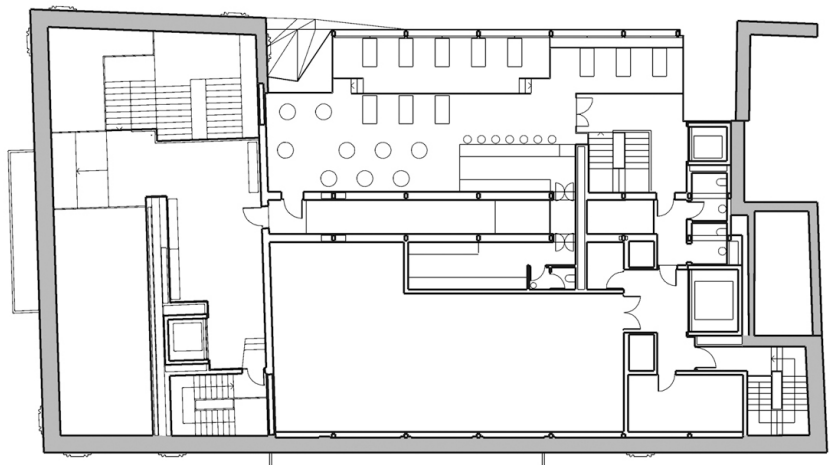

Nivel 3

Figura 3. Plantas de distribución. 


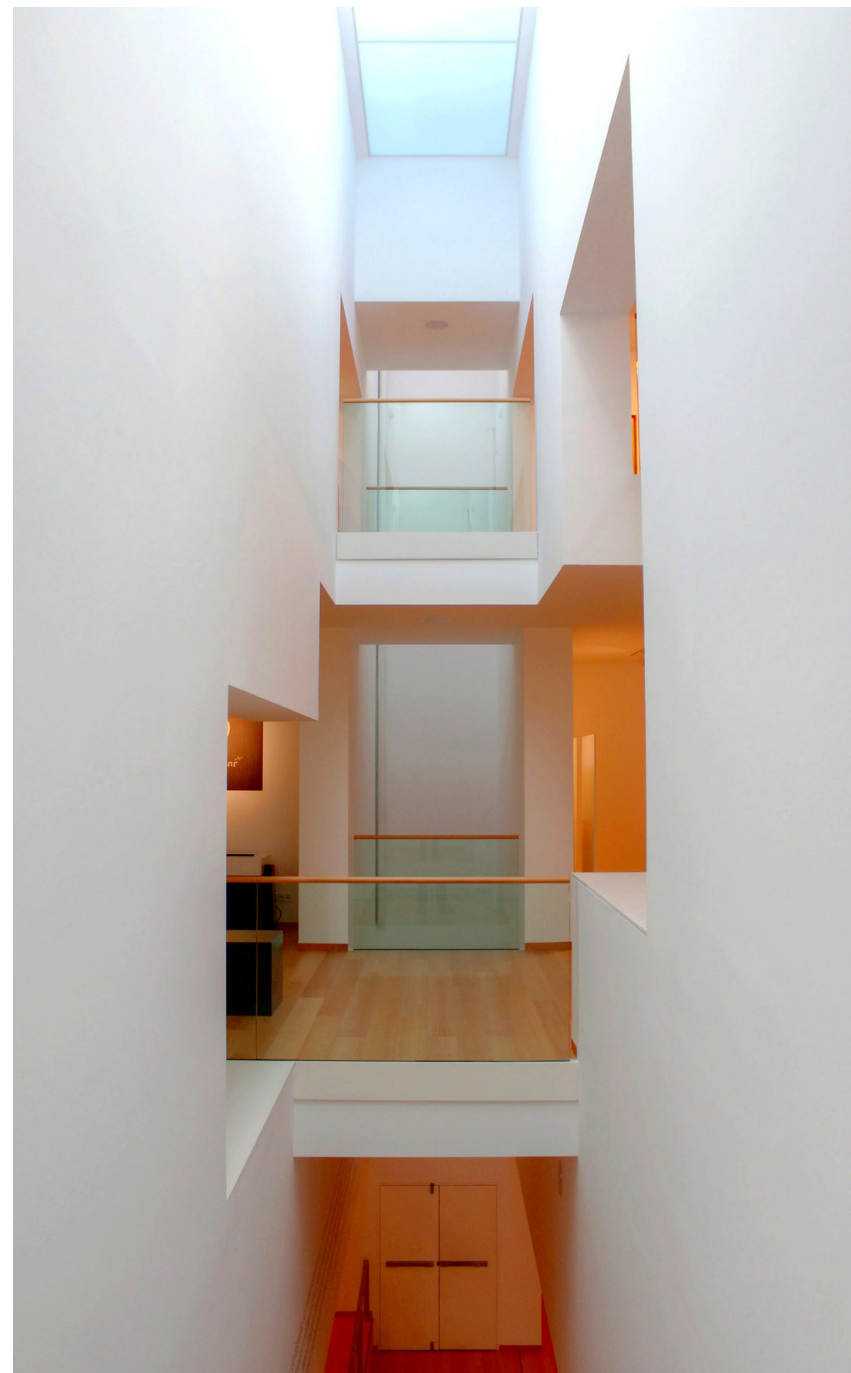

Figura 4. Lucernario central.

el espacio expositivo a la totalidad de la superficie, de modo que dichos planos portantes no debían incluir soportes a esa cota, y sí salvar en consecuencia una luz de 17,70 m bajo las importantes acciones gravitatorias procedentes de las áreas contiguas. Adicionalmente, este vacío central aparece atravesado en diversos puntos por pequeños puentes de comunicación, configurando un intrincado juego volumétrico.

A fin de satisfacer todos estos condicionantes, se diseñaron dos vigas pared en celosía, abarcando tres alturas de la nueva construcción (Figuras 7). Particularmente en su ámbito central fue preciso alterar la distribución regular de montantes y prescindir de diversas diagonales, siempre de acuerdo con la posición de las diferentes pasarelas. Ambos conjuntos se vinculan a sendas pantallas de hormigón armado. En el ámbito interior se definen secciones de $120 \times 30 \mathrm{~cm}$, que rematan a cota de planta primera, y junto a la medianera un núcleo con una configuración en $\mathrm{C}$ que finaliza en el nivel bajo cubierta. En dirección longitudinal, éste presenta pantallas de $195 \times 25 \mathrm{~cm}$, con sus extremos libres rematados mediante tubos \#200.250.8 (con horquillas horizontales de conexión) a fin de facilitar los oportunos enlaces. El apoyo directo de las vigas pared sobre los elementos de hormigón, unido a su carácter autoportante, redujo notablemente la necesidad de medios auxiliares de apeo (Figura 8). Asimismo, la conexión en un extremo a pantallas de cierta longitud, y el

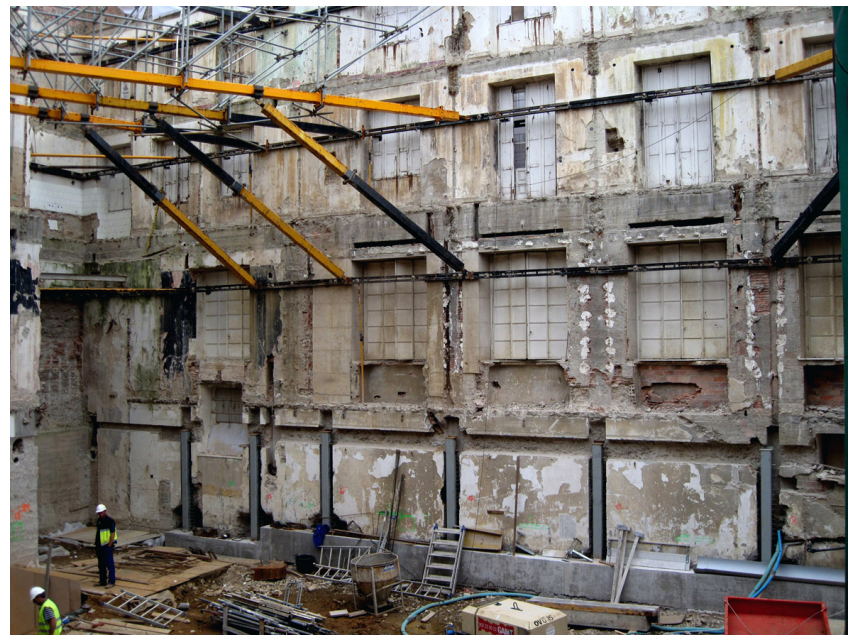

Figura 5. Fachada de la calle Xelmírez.

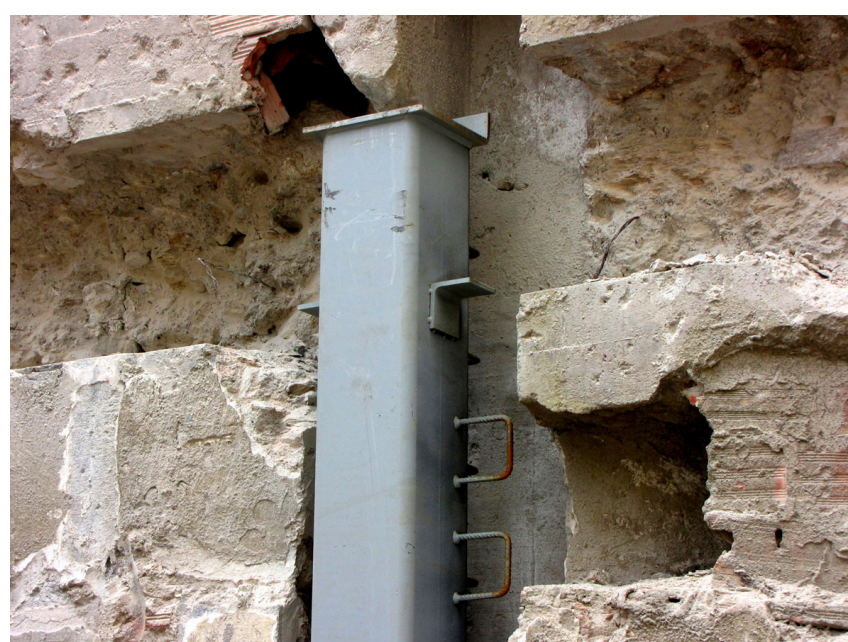

Figura 6. Detalle de soporte tubular.

vuelo opuesto con enlace final a pórtico transversal permitieron ajustar la deformación por flexión positiva a valores plenamente admisibles. Todas las piezas se diseñaron con sección tubular conformada o en cajón, adaptando dimensiones y espesores a fin de armonizar las deformaciones de ambas vigas, que, como se ha apuntado, no presentaban la misma configuración formal ni estaban sometidas a valores similares de carga.

\section{FACHADA VÍTREA}

Entre el lucernario central y la calle de la Conga se ubican diferentes salas de menor superficie, pero con una cierta singularidad espacial derivada de la inclusión de espacios a doble y triple altura bajo el local de cafetería directamente emplazado en el ático. La nueva fachada se asienta sobre un zócalo de grandes piezas graníticas, y asciende desde el mismo mediante un gran plano de vidrio que finalmente se diluye en el lucernario corrido de cafetería (Figura 9). Se trata de un complejo cerramiento compuesto por una doble hoja de vidrio selectivo de control solar, en la que la mezcla de láminas diferentes (transparentes y mateadas) busca un curioso efecto óptico, mezcla de materialidad y ligereza (5). Entre ambas hojas discurre un esqueleto estructural constituido por diversos tipos de sección. En el caso de los dinteles se utilizan cajones metálicos ampliamente horadados en ambas alas, con objeto de que la totalidad de la fachada configure 


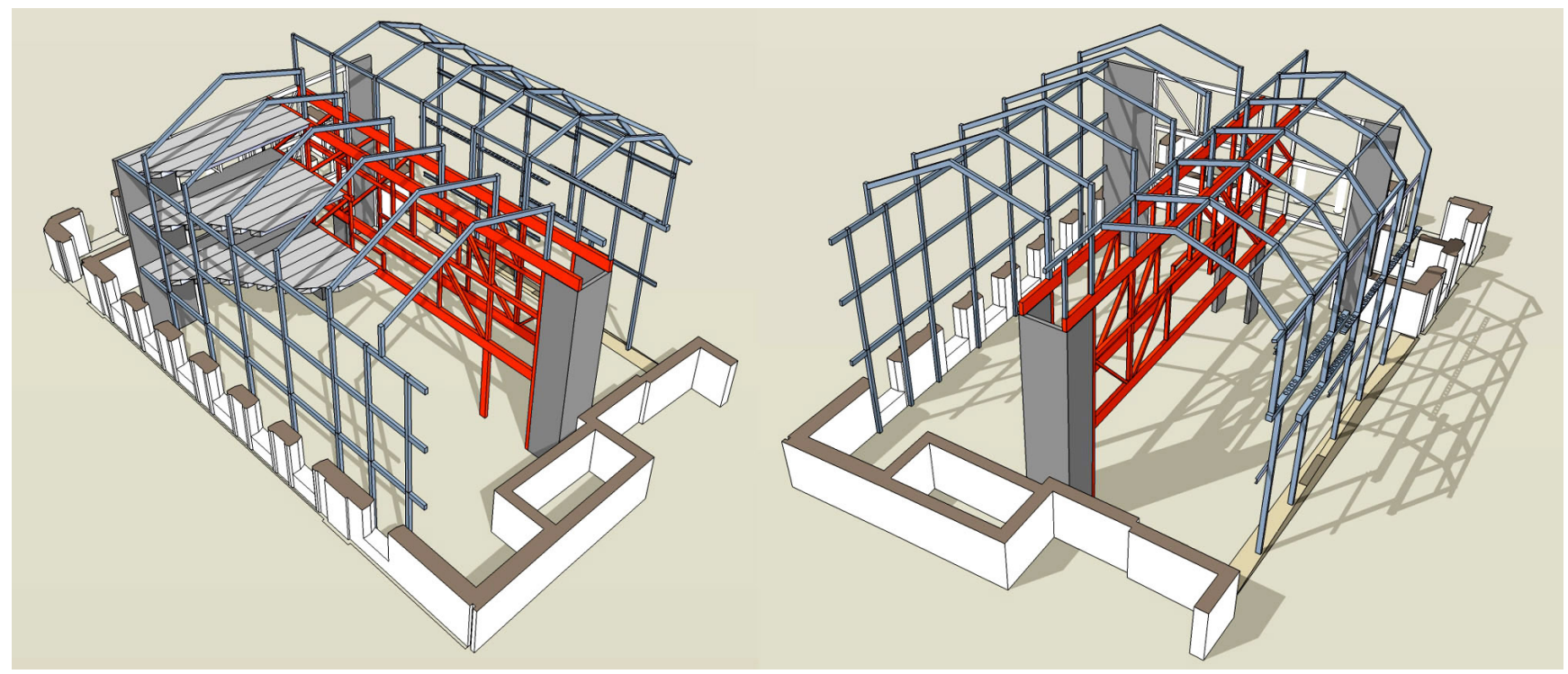

Figura 7. Vista parcial del sistema, reseñando las grandes vigas interiores.

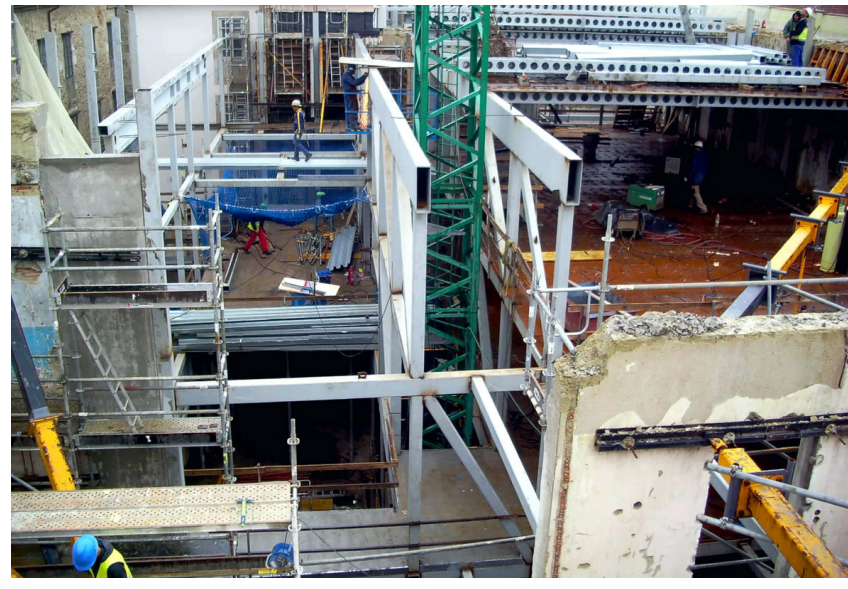

Figura 8. Disposición de forjados sobre las vigas en celosía.

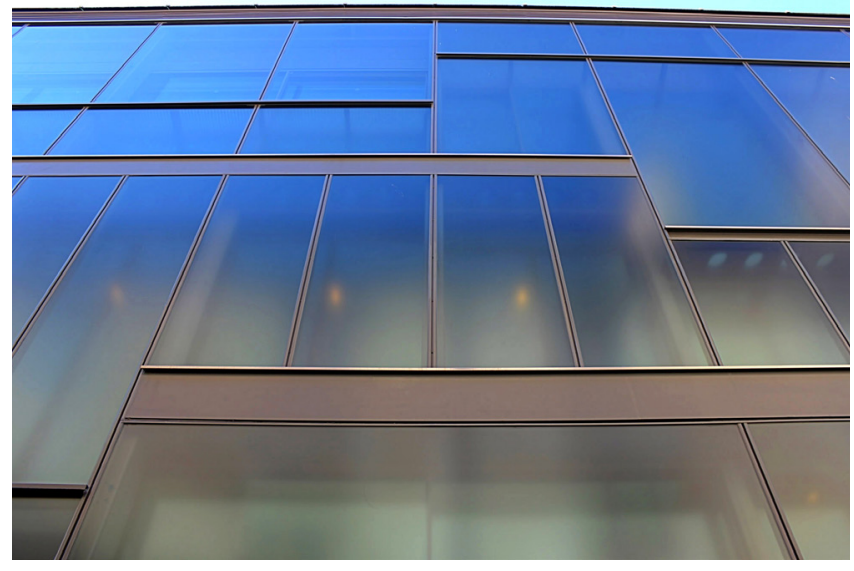

Figura 9. Fachada vítrea a la calle de la Conga.

una gran cámara de aire ventilada, desde el sótano hasta la línea de cornisa (Figura 10).

En el encuentro con el paramento preexistente el plano de vidrio se pliega y retrasa, dando lugar a una configuración facetada que remata superiormente en un prominente lucernario sobre el ámbito de la escalera principal (Figura 11).

$\mathrm{Al}$ interior se ha previsto un pórtico intermedio que sirve de soporte a un tercer plano de cerramiento. Éste, a su vez, mediante una nueva solución multicapa de vidrios, paneles correderos y láminas pivotantes, se encarga de resolver el control lumínico de las áreas expositivas, tamizando o anulando en su caso los efectos de la fachada vítrea.

\section{SOLUCIONES DE FORJADO}

Los condicionantes ya mencionados de transporte y suministro fueron en último término determinantes en el momento de definir la configuración de los forjados de mayor luz, que, por corresponder igualmente a áreas expositivas, debían soportar valores notables de sobrecarga. A estas limitaciones se unía una estricta limitación de espesores, derivada de la conservación de fachadas, y de la altura libre exigible por cuestiones de programa. Tales consideraciones

supusieron un canto estructural máximo de $35 \mathrm{~cm}$, que por otra parte debía de incorporar aligeramientos para el paso de instalaciones.

Por ello se desecharon soluciones pre o postesadas, que en otra coyuntura habrían resultado adecuadas, y se diseñó un forjado constituido por vigas cajón metálicas con almas alveoladas y capa superior de compresión en hormigón (Figuras 12 y 13). La adopción de un forjado mixto responde también a diversos requisitos funcionales, como son el control de la frecuencia propia ante posibles vibraciones, la limitación de las deformaciones máximas o el adecuado acondicionamiento acústico de las salas. Para favorecer la colaboración entre ambos materiales se dispusieron conectores horizontales mediante barra corrugada soldados al ala superior de las vigas cajón. Se utilizaron estos elementos, en lugar de otro tipo más convencional de conectores, con el objeto de reducir en lo posible el espesor de la capa superior de hormigón. Asimismo, y con objeto de garantizar la deformación conjunta de toda la placa, se proyectó una alineación central de rigidizadores conectando en sentido transversal todas las piezas. Esta solución permitió salvar luces de 9,80 m con un peso total de $2,95 \mathrm{kN} / \mathrm{m}^{2}$, valor muy inferior al que implicarían, por ejemplo, soluciones de losa alveolar pretensada (en el ámbito de 5,00 a $5,50 \mathrm{kN} / \mathrm{m}^{2}$ ) o de losa postesada $\left(>6,25 \mathrm{kN} / \mathrm{m}^{2}\right)$. Esta reducción de peso 


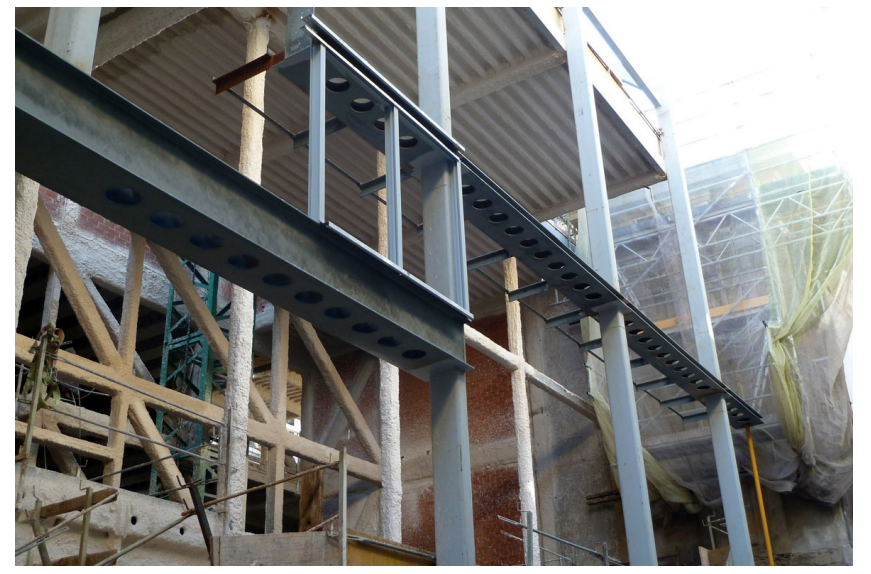

Figura 10. Fachada vítrea en fase de ejecución.

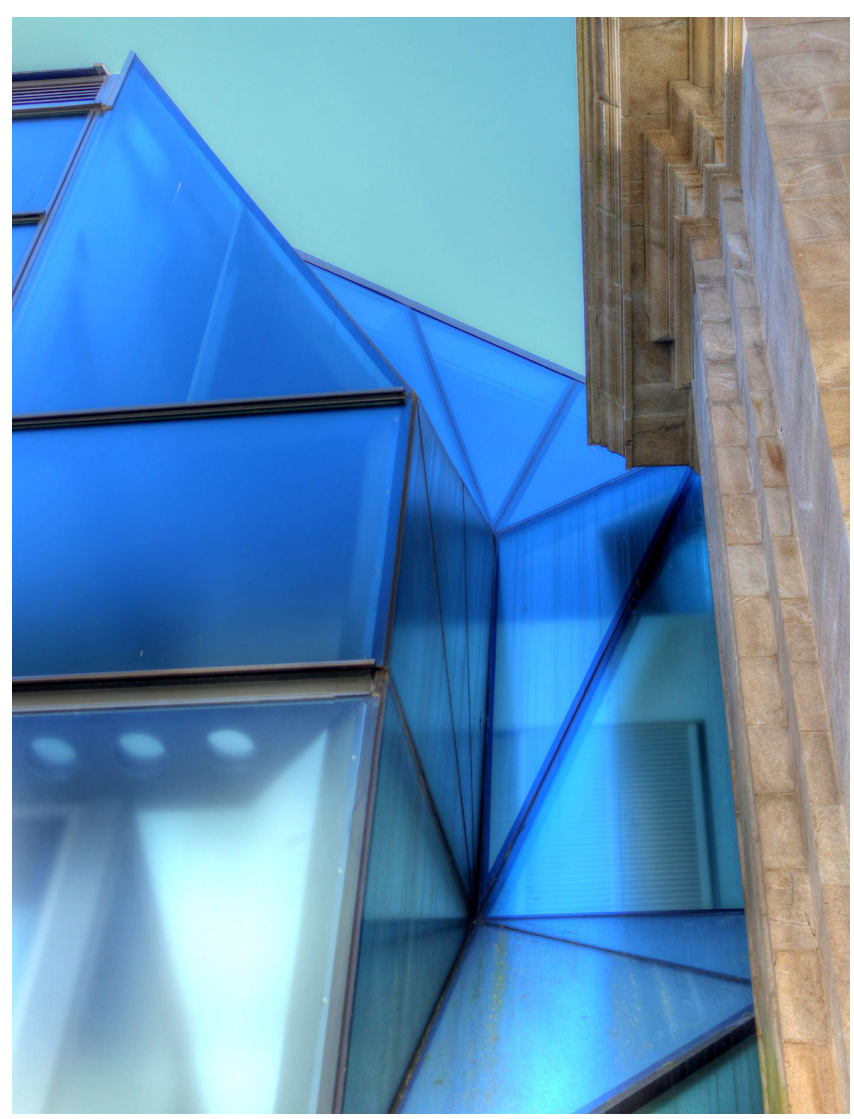

Figura 11. Ámbito facetado como conexión entre la fachada vítrea y la preexistente.

resulta igualmente crucial en el dimensionado de las grandes vigas pared interiores, en particular si se considera la amplia banda de carga que gravita sobre las mismas.

Cabe apuntar que los casos singulares, vinculados al apeo de soportes sobre la propia placa o a la resolución de huecos en la misma, se resolvieron utilizando el mismo esquema, si bien incrementando el espesor de las correspondientes alas.

Las alas superiores de las vigas cajón que configuran el forjado descrito incorporan vuelos extremos que resuelven su apoyo directo sobre las jácenas (con la mera interposición de una banda continua de neopreno) (Figura 14). De esta forma se facilita extraordinariamente su colocación en obra sin la necesidad de utilizar apeos provisionales. Una vez pre-

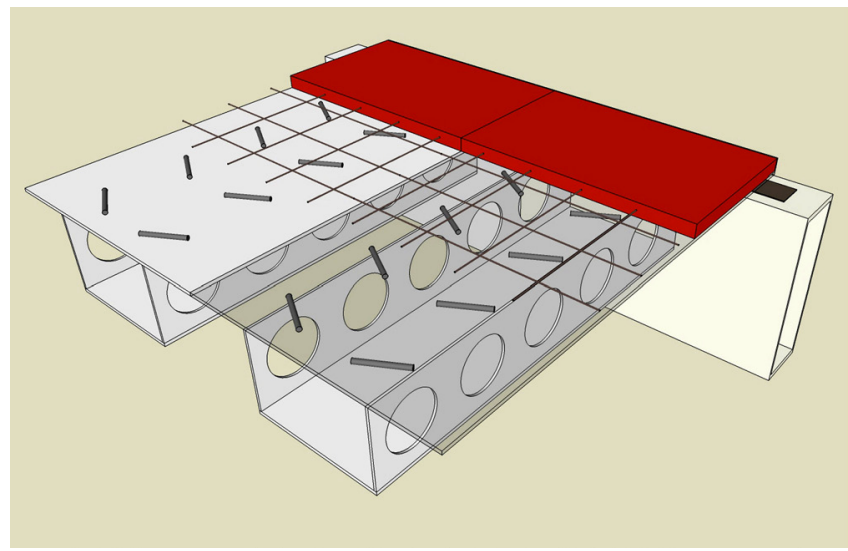

Figura 12. Esquema de forjado.

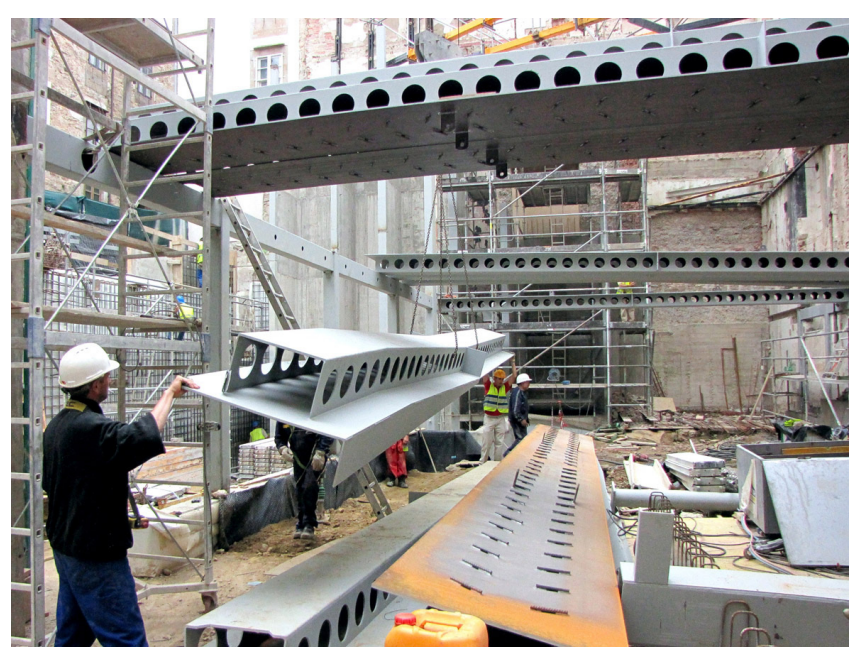

Figura 13. Disposición de vigas cajón.

sentado el cajón en su posición definitiva, las conexiones se complementan mediante las clásicas soldaduras de alma.

En los ámbitos de vano cuya dimensión no exigía una solución singular como la anterior, se recurrió a paños de forjado colaborante Hiansa MT-100, con un canto total de $140 \mathrm{~mm}$, variando el espesor de la chapa según los distintos requerimientos resistentes. En todos los casos, con el fin de conformar secciones mixtas que redujesen la deformabilidad de los correspondientes planos estructurales, se recurrió a la utilización sobre las vigas de conectores de tipo Hilti X-HVB 110, fijados mediante autodisparo (Figura 15).

Como excepción únicamente se plantea el techo del ámbito de soportal, vano en el que se decidió mantener una configuración formal similar a la precedente. Por ello aquí se proyectó una losa unidireccional de hormigón armado, constituida por nervios de sección $15 \times 40 \mathrm{~cm}$, espaciados cada $50 \mathrm{~cm} \mathrm{y}$ vinculados por una placa continua de $10 \mathrm{~cm}$ de espesor. La conexión a los muros de hormigón ciclópeo extremos se resolvió mediante repicado de los mismos y anclaje de barras corrugadas con inyección de resina epoxi (Figura 16).

\section{ITINERARIO INTERIOR}

Dado el carácter temático del museo, y su localización al pie del conjunto monumental, se planteó incorporar de alguna forma el recorrido expositivo al propio itinerario 
de peregrinación. De este modo, la escalera principal se concibe como parte del camino (Figura 17), definiendo una ruta ascendente que culmina en la cornisa oeste, donde una serie de aberturas, dispuestas estratégicamente en cubierta, ofrecen singulares encuadres de la catedral románica (Figura 18). Bajo estas reflexiones la escalera se define como un elemento escultórico, concepto que se acentúa en los tramos superiores en vuelo. Desde un punto de vista estructural se resuelve íntegramente mediante chapa de acero, tanto en la materialización del peldañeado como en la del antepecho.

\section{SINGULARIDADES A NIVEL DE CIMENTACIÓN}

En 2008 se afronta un estudio geotécnico a petición del Consorcio de Santiago, incluyendo calicatas, ensayos de penetración dinámica (alcanzando una profundidad máxima de 4,40 m), sondeos a rotación con recuperación continua de testigo (hasta los 9,10 m desde la cota de inicio), y diversos ensayos de laboratorio. De esta forma se reconocieron las características litológicas del subsuelo, los niveles de empotramiento de los muros existentes, y las características de los materiales de apoyo de las nuevas cimentaciones. Dada la cota prevista de asiento, y los resultados de la campaña, el citado estudio recomienda una cimentación superficial mediante zapatas, considerando una tensión admisible del terreno de hasta $4,00 \mathrm{Kp} / \mathrm{cm}^{2}$, tanto en los ele-

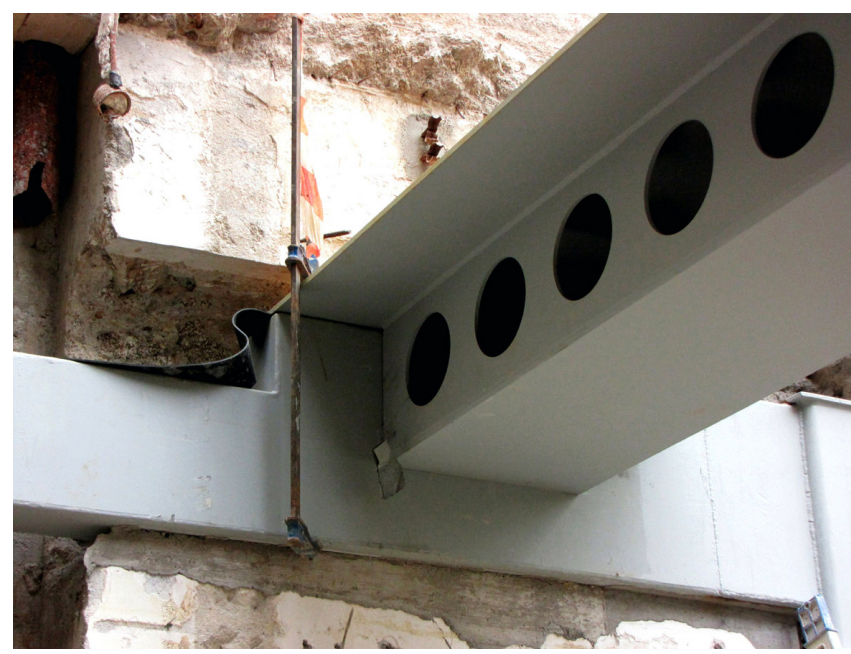

Figura 14. Solución de apoyo de viga cajón.

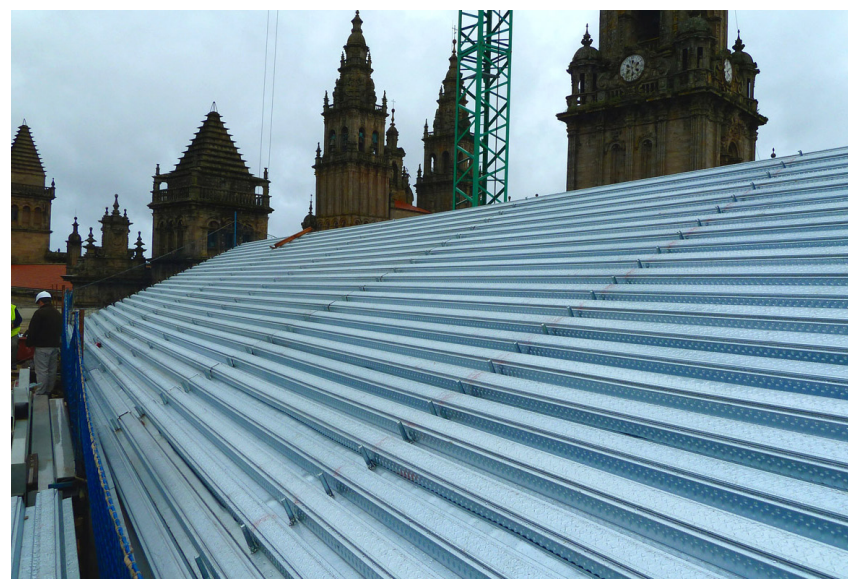

Figura 15. Resolución de cubiertas mediante forjados de chapa colaborante. mentos nuevos como en los niveles de apoyo de los muros a conservar.

No obstante, la excavación bajo la primitiva cámara acorazada del banco reveló algo en principio imprevisto: junto a los cimientos de las casas que ocupaban el solar de Platerías antes de la construcción de la propia sede bancaria, se destapó una fracción del sistema defensivo del siglo X (básicamente el foso que en aquella época rodeaba la muralla y la plataforma de asentamiento de ésta).

Este suceso tuvo dos consecuencias relevantes. En primer lugar fue necesario coordinar las actividades propias de la obra con la labor del equipo de arqueólogos encargado de efectuar el levantamiento detallado de los restos. En este aspecto jugaron un papel destacado los forjados metálicos antes descritos, pues la correspondiente luz de vano, unida al carácter autoportante de los mismos, permitió continuar la construcción en los niveles superiores mientras se ultimaban las tareas de investigación arqueológica (Figura 19). Asimismo, se prohibió expresamente la realización de cualquier tipo de cimentación superficial que pudiese afectar al área protegida, siendo por tanto necesario recurrir en la misma a soluciones de micropilotaje.

Por otro lado, se decidió incorporar el descubrimiento al contenido del museo, considerando su vocación como cen-

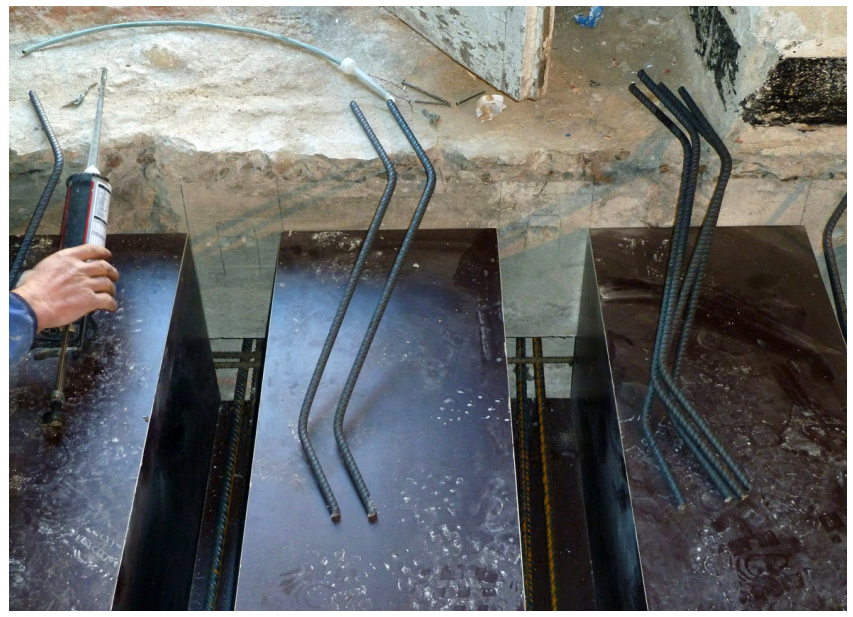

Figura 16. Conexión de nervios in situ a fachadas de hormigón ciclópeo.

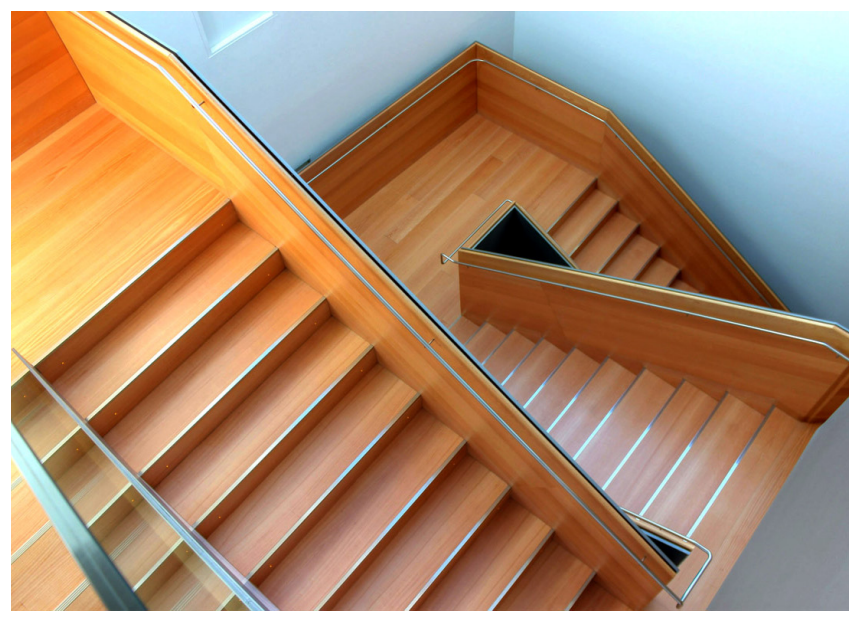

Figura 17. Escalera principal. 


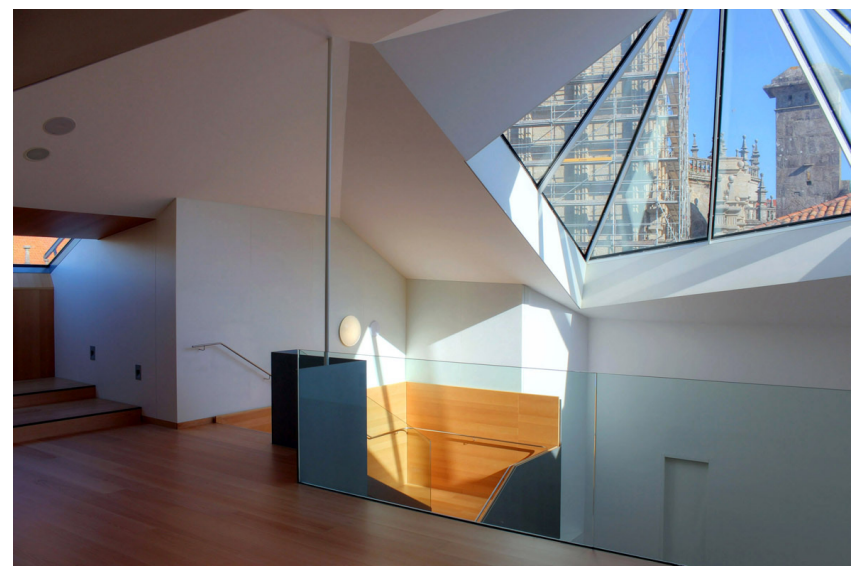

Figura 18. Lucernarios en la coronación de escalera.

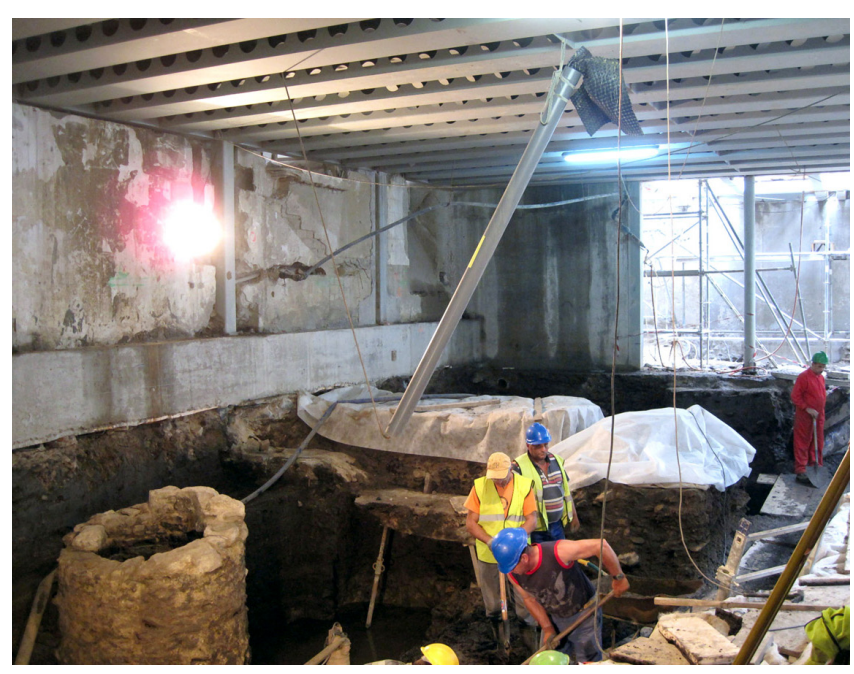

Figura 19. Restos arqueológicos.

tro de referencia de interpretación de la ciudad. Esta decisión obligó a incrementar la profundidad de excavación en toda una banda adyacente a la calle Xelmírez, situándose del orden de $4 \mathrm{~m}$ por debajo de su cota, y descalzando en consecuencia la fachada preexistente, a la que por otra parte era necesario adosar un nuevo entramado estructural. A tales efectos se optó por definir bajo cada soporte tubular un encepado de $75 \mathrm{~cm}$ de canto, asentado sobre un trípode de micropilotes de tubo Ø101.6x9.0 con una penetración mínima de $3 \mathrm{~m}$ en el sustrato rocoso (Figura 20). Entre dichas piezas se dispuso otra longitudinal de atado, con una sección transversal uniforme de $35 \times 50 \mathrm{~cm}$, que incluía un micropilote adicional intermedio, y un recrecido de hormigón arma-

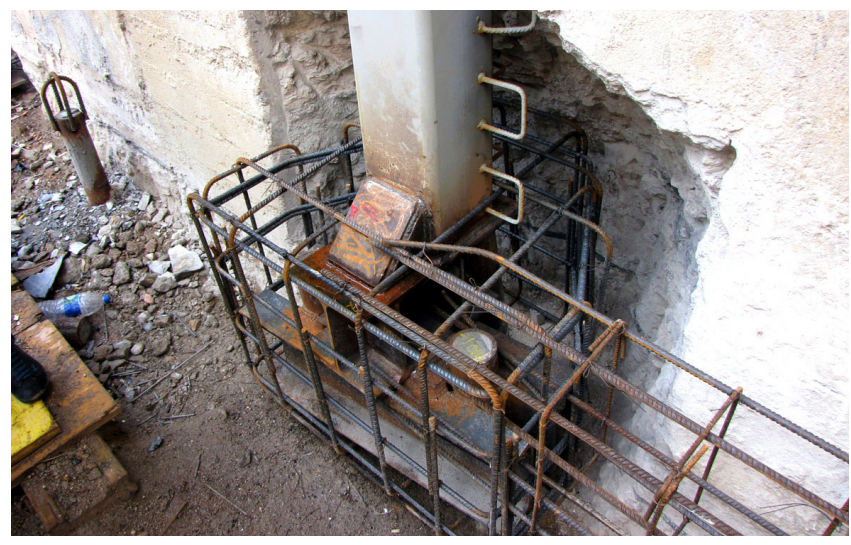

Figura 20. Cimentación profunda en la base de la fachada a la calle Xelmírez.

do (sobre el cimiento previo) para configurar el paramento interior en la zona afectada por el primitivo foso. Todas las operaciones se efectuaron desde el interior del solar y desde la planta superior, a fin de no alterar el área protegida y de no entorpecer el uso de la vía pública ni deteriorar su histórico pavimento pétreo.

\section{A MODO DE CONCLUSIÓN}

El Museo de las Peregrinaciones de Santiago de Compostela constituye un extraordinario ejercicio de intervención dentro de un entorno monumental. Manuel Gallego ha creado en él un conjunto expositivo de gran riqueza espacial, en íntimo diálogo con la Catedral y la historia de la ruta jacobea.

En un marco tan complejo, la elección de soluciones de estructura metálica como las descritas ha derivado en una notable flexibilidad a la hora de diseñar propuestas diáfanas, de reducido peso propio, y susceptibles de ser fabricadas y transportadas en fracciones acotadas para su posterior ensamblaje en obra.

Asimismo, el entramado propuesto, asentado sobre un reducido número de elementos interiores de soporte, ha permitido avanzar en el grueso de la obra minimizando las posibles interferencias con los equipos de investigación arqueológica.

Constructora: UTE Geotécnica y Cimientos, S.A., Neor S.A., y Dragados S.A.

Control de calidad: Incosa

Estructura metálica: Comonor

Cubiertas: Cubregal S.L.

Carpintería exterior metálica: Acira Metal S.L.

\section{REFERENCIAS}

(1) Engroba-Cabana, S. (2008). Crear y recrear un museo: el Museo de las Peregrinaciones de Santiago. Museo, 13: 344-353.

(2) Corral-Varela, J.M. (1995). La polémica construcción del edificio del Banco de España en Santiago: peripecias de postguerra. Cuadernos de Estudios Gallegos, 42(197): 339-36o, doi: http://dx.doi.org/10.3989/ceg.1995.v42.i107.

(3) Ministerio de Fomento. (2009). CTE DB SE-AE. Seguridad Estructural, Acciones en la Edificación.

(4) González-Rodríguez, S. (1984). Vaciado de edificios conservando la fachada. Informes de la Construcción, 36(363): 5-20, doi: http://dx.doi.org/10.3989/ic.1984.v36.i363.1914.

(5) Gallego-Jorreto, M. (2012). Museo de las Peregrinaciones, Santiago de Compostela. Tectónica, 39: 60-81. 